\title{
Leaders
}

\section{Exercise in old age: time to unwrap the cotton wool}

To some the concept of promoting exercise and other lifestyle changes in old age is bizarre. Skeptics argue that, as many of the chronic degenerative diseases have their origins much earlier in life, realistic opportunities have been comprehensively missed. Furthermore, although it is well known that people with lower health risks tend to live longer, some contend that promoting healthier lifestyles in old age may result in an expanding population of frail dependent old people. The fear is that healthier habits in later life may actually increase morbidity (and health care costs) by increasing the number of years survived with chronic illness and disability. However, this view has been challenged by the results of an extraordinary longitudinal follow up study of people graduating from the University of Pennsylvania in 1939 and $1940 .{ }^{1}$ It showed that smoking, body mass index, and exercise patterns in midlife and late adulthood are predictors of subsequent disability. Not only did people with better health habits survive for longer, but the age at onset of disability was postponed and compressed into fewer years at the end of life.

Demonstrating that exercise can be beneficial in old age is, however, less difficult than persuading people to be physically active. Two major obstacles exist. The first is the common misconception that, to reap health benefits, vigorous continuous exercise is necessary. This misunderstanding can be traced to recommendations derived from studies of the effects of endurance exercise training in younger adults. These recommendations were disseminated in terms so complex, scientific, and prescriptive that for many sedentary and elderly people the notion of exercise and physical fitness became meaningless. However, a reassessment of this evidence has shown that most health benefits could be gained at lower doses of physical activity. ${ }^{2}$ It is regrettable that, despite this recognition, public health advice has failed to shake off the "high-tech" lycra clad image of aerobic exercise and physical fitness, and embrace the concept of health and physical activity - walking, dancing, gardening, or playing with the grandchildren. The effectiveness and acceptability of this approach has been shown in a clinical trial in sedentary adults in which a physical activity intervention proved as effective as a structured exercise programme in improving activity levels, cardiorespiratory fitness, and blood pressure. ${ }^{3}$ The main attraction of the physical activity approach is that, although to adopt and maintain a moderate level of physical activity is within the reach of many elderly people, the prospect of vigorous exercise is a major turn off. ${ }^{4}$ Old people are more likely to be motivated to be active when they appreciate that the benefits are likely to be reflected in their health and in preserving their functional capacity.

The second major obstacle is the exaggerated fear, mainly in the minds of the medical profession, of the risks of physical activity in old age. The sedentary state has become so all pervasive that we have lost sight of the fact that physical activity is part of normal, reasonable, health enhancing behaviour across the age spectrum. Inactivity in old age is reinforced by stereotypical views on the inevitability of decline with aging and on a lack of understanding of the trainability of even very elderly muscles. The dangers of the sedentary state in old age were highlighted by a study of institutionalised elderly people in which the functional capacity of a control group of sedentary residents deteriorated measurably in just six months, while a seated exercise programme for 30 minutes twice a week resulted not just in preservation of function, but in some restoration of lost function. ${ }^{5}$ An extensive literature on exercise studies in elderly people now exists and is notable for its absence of reports of serious adverse events. Although safety is of paramount importance, several exercise studies in institutionalised frail elderly people have been conducted safely, applying no exclusions on pre-morbid medical condition, medication, or any other basis. ${ }^{5}$ In addition, the University of Dundee's over 60 s exercise class, for example, attracts 1000 pensioners each week, and also operates on a no screening, no disclaimer, all comers accepted basis. ${ }^{7}$ Twenty years of experience accounting for more than 500000 hours of pensioner exercise time has been accrued without incurring a serious adverse event. This inclusive approach contrasts with other workers whose screening procedures and criteria for exclusion were such that $43 \%$ of old people wishing to join an exercise research programme were excluded. ${ }^{8}$ Unfortunately the medical profession has so far devoted too much of its energy to finding reasons why older people should not exercise, and too little to why they should. If an activity is not provoking symptoms, it is very unlikely to be doing harm. Elderly people should not be discouraged from continuing with, or adopting, activities that are enjoyable, as enjoyment is the single strongest predictor of adherence to an activity programme.

Compelling evidence exists of the benefits of regular physical activity in old age. Despite this, many health professionals lack the skills, knowledge, inclination, and reimbursement to routinely counsel old patients about physical activity, although this has been shown to be effective. ${ }^{9}$ Elderly people must be informed that regular physical activity is both appropriate and desirable in old age, and the older community should be involved in developing a range of services and facilities to back this up. Imaginative partnerships between leisure and recreation facilities, parks departments, and town planners are required to make changes in our social and physical environment to ensure that it is a safe and attractive place in which to be active. It is of concern that some elderly people live in care settings in which physical activity is an unfamiliar or even a frightening concept, and initiatives are urgently required to change attitudes in hospitals, homes, sheltered housing complexes, and day care centres. A public health approach to an aging society is long overdue and should explore opportunities and incentives for healthy lifestyles.

Conflict of interest: METM is co-director of D D Developments, a University of Dundee company, the mission of which is to provide exercise classes for older people, and the profits of which support research into ageing and health.

Department of Medicine, University of Dundee MARION E T MCMURDO

1 Vita AJ, Terry RB, Hubert HB, et al. Aging, health risks, and cumulative disability. N Engl f Med 1998;338:1035-41.

2 Physical activity and public health. A recommendation from the centers for disease control and prevention and the American College of Sports Medicine. FAMA 1995;273:402-7. 
3 Dunn AL, Marcus BH, Kampert JB, et al. Comparison of lifestyle and structured interventions to increase physical activity and cardiorespiratory fitness: a randomised trial. $\mathcal{F A M A}$ 1999;281:327-34.

4 Pollock ML. Prescribing exercise for fitness and adherence. In: Dishman RK, ed. Exercise adherence. Champaign, IL: Human Kinetics Publishers, 1998:259-77.

5 McMurdo MET, Rennie L. A controlled trial of exercise by residents of old peoples' homes. Age Ageing 1993;22:11-15.
6 McMurdo MET, Rennie L. Improvements in quadriceps strength with regular seated exercise in the institutionalised elderly. Arch Phys Med Reha$4 \cdot 75 \cdot 600-3$

7 McMurdo MET, Burnett L. Randomised controlled trial of exercise in the elderly. Gerontology 1991;334:1-7.

8 Posner JD, Gorman KM, Klein HS, et al. Exercise capacity in the elderly. Am f Cardiol 1986;57:52C-8C

9 Calfas KJ, Long BJ, Sallis JF, et al. A controlled trial of physician counselling to promote adoption of physical activity. Prev Med 1996;25:225-33.

\section{Perpetuating ignorance: intravenous fluid therapy in sport}

Intravenous fluid therapy is quite often advocated as the essential component in the management of athletes requiring medical care after prolonged exercise..$^{1-4}$ It is presumed that such fluids are essential for the rapid reversal of the dehydration that is the principal cause of their condition. The basis for this belief has been challenged elsewhere. ${ }^{5-10}$ Two articles in a recent issue of this journal invite the renewal of that debate and specifically pose the question: what is the role of acute intravenous fluid therapy in sport?

In the first paper, Herfel et $a l^{11}$ report the iatrogenic development of acute hyponatraemia in a college football player who had initially presented to a doctor complaining of leg cramps after a football practice. Presumably because he believed that dehydration, hypoglycaemia, or sodium depletion, or all three, cause exercise related muscle cramps, the doctor prescribed treatment with a total of 8 litres of intravenous and oral fluid, 3 litres by mouth and another 5 litres of $0.45 \%$ saline with $5 \%$ dextrose intravenously over a five hour period. The duration of the football practice, the player's weight and playing position, the nature of the day's practice, and the prevailing environmental conditions are not reported. This information would help in predicting the likely sweat rates and fluid losses and hence the probable level of dehydration incurred by the player.

If dehydration is indeed the main cause of exercise related muscle cramps, the first clinical question requiring attention is: what is the probability that this football player could have sustained an $8 \mathrm{~kg}$ weight loss during the football practice and hence require the relatively rapid replacement of 8 litres of fluid after exercise?

Sweat rates as high as $1000-1750 \mathrm{ml}$ per hour have been measured in athletes involved in continuous exercise of moderate to high intensity, ${ }^{12}$ with the higher values typically occurring in runners in the humid conditions prevalent in many Asian countries and in the summer in the Southern United States, where this football player trained. Conceivably, heavy players practising an intermittent sport like American football in hot humid conditions while wearing football uniforms may also achieve such high sweat rates. Hence, to have become dehydrated by 8 litres, this particular athlete would have had to have practiced for between four and a half and eight hours without ingesting any fluid. Doctors knowledgeable of that game would be better able to judge whether or not this is a common or likely occurrence in college football in the United States. It seems unlikely that a college football player would not drink during training, given the frequently asserted injunction that all athletes should ingest fluid frequently and in large volumes during exercise, especially in the heat. ${ }^{13}$

The point is that those who choose to give fluids intravenously to athletes should have at least some idea of the likely fluid losses that athletes involved in different sports will incur, so that the volumes prescribed are likely to be reasonable and appropriate.

For example, the highest levels of dehydration reported in marathon runners, competing in races in which fluids are not freely available, are usually of the order of $4 \%$ of body weight. ${ }^{12}$ Accordingly, if intravenous fluid therapy is considered desirable, there would seldom be any justification for giving much more than 1-2 litres of fluid to endurance athletes, equivalent to $2-4 \%$ body weight in $50-70 \mathrm{~kg}$ athletes.

In fact the magnitude of the iatrogenic fluid overload in the football player described by Herfel et $a l^{11}$ can probably be estimated from the data provided. Our study ${ }^{14}$ found a linear relation between the serum sodium concentration and the degree of fluid overload in ultramarathon runners with severe symptomatic hyponatraemia. In that study a serum sodium concentration of $121 \mathrm{mmol} / \mathrm{l}$, as measured in this football player, was associated with a minimum fluid excess of about 4 litres. This suggests that the football player with muscle cramps probably lost about 4 litres of fluid during his practice, suggesting a likely practice time of about two and a half hours, if no fluid was ingested during the practice. Oral fluid therapy of a maximum of 4 litres during recovery would therefore have been the more appropriate therapy for this player.

The most likely reason why iatrogenic hyponatraemia occurs under these circumstances is because the patient's response to treatment is monitored so that fluid continues to be administered until the primary condition resolves. Thus, if the condition fails to respond to treatment, the natural response is simply to give more of the same. However, the more astute clinician would be forced to ask whether a failure to respond to treatment may indicate that the prescribed treatment is inappropriate for the specific condition being treated. This then raises the next relevant question: what evidence is there that muscle cramps (or indeed any of the so called exercise related "heat disorders") are due solely and exclusively to dehydration so that fluid therapy is the sole reasonable form of treatment?

As reviewed in detail elsewhere ${ }^{78}$ there is no published evidence whatsoever that muscle cramps are due to dehydration, or that dehydration is an important causative factor in either "heat exhaustion"-an inappropriate term because athletes with this condition do not show any evidence of excessive heat retention, ${ }^{7815}$ but are more probably incapacitated by a posture related hypotension that develops on the cessation of exercise-or even in heat stroke. Thus weight loss during exercise is no greater in runners chronically prone to exercise induced muscle cramping and who develop cramps during ultramarathon races than it is in control runners who do not cramp. ${ }^{16}$ Nor is there any published evidence that cramps are related exclusively to dehydration in any setting yet described. ${ }^{8}$ Rather, muscle cramps are probably related to neurological changes that develop as a result of exercise related neuromuscular fatigue. ${ }^{17} 18$ 
Hence the iatrogenic hyponatraemia described in the patient, successfully resuscitated with "masterful inactivity" ${ }^{\prime 6}$ as correctly prescribed by Herfel et al, ${ }^{11}$ was caused by the overenthusiastic treatment with oral and intravenous fluids of a condition that has no known relation to dehydration.

In the second study, $\mathrm{Nagra}^{19}$ reports a controlled trial of the efficacy of intravenous fluid therapy in subjects recovering from a 45 minute bout of exercise that induced a $1.2 \%$ dehydration level. When exercise recommenced 16 minutes later, subjects given the same volume of fluid either orally or intravenously did not differ in their exercise capacity or in their ratings of perceived exertion. This study complements that of Polak et al, ${ }^{20}$ also published in the Journal, which found that intravenous infusion of 2.5 litres of a similar solution immediately after the race did not influence the rate of recovery of athletes completing the Rotterdam marathon.

$\mathrm{Nagra}^{19}$ suggested that, until contradictory evidence based results are available, athletes should take their fluids orally, not intravenously-if, that is, they are truly dehydrated and in need of rehydration.

In summary, the importance of these reports is to show that, if one uses an inappropriate treatment for a specific condition, the most favourable outcome will be that neither good nor harm will result; the worst result will be that an iatrogenic condition, in this case, hyponatraemia will result. One needs to remember that hyponatraemia can produce a fatal outcome, especially tragic when a healthy fit athlete is treated inappropriately. I continue to argue that it is time for us to cease promoting the idea that dehydration alone causes the so called "heat disorders" and to begin to read the literature with a more discerning eye. For too long we have perpetuated ignorance because of a profound resistance to replace $\operatorname{dogma}^{21}$ when all the contrary evidence is available. ${ }^{78}$ Must a collapsed marathon runner ${ }^{121422}$ or army recruit, or a football player with muscle cramp, ${ }^{11}$ die from iatrogenic hyponatraemia before we finally question our ignorance?

MRC/UCT Bioenergetics of Exercise Research Unit,

TIMOTHY D NOAKES

Department of Physiology, University of Cape Town,

Boundary Road, Newlands, 7700, South Africa

1 Adner MM, Scarlet JJ, Casey J, et al. The Boston Marathon Medical Care Team: ten years of experience. Physician and Sportsmedicine 1988:16:99-106. 2 Eichner ER. Sacred cows and straw men. Physician and Sportsmedicine 1991: 19:24.

3 Hiller, WDB. Dehydration and hyponatremia during triathlons. Med Sci Sports Exerc 1989:21:S219-21.

4 Maughan, RJ, Shirreffs, SM. Fluid and electrolyte loss and replacement in exercise. In: Harries M, Williams C, Stanish WD, eds. Oxford textbook of sports medicine, 2nd ed. Oxford: Oxford University Press, 1998:106.

5 Noakes, TD. Sacred cow revisited. Physician and Sportsmedicine 1991:19:49.

6 Noakes TD. Why marathon runners collapse. S Afr Med f 1988:73:569-71.

7 Noakes TD. Dehydration during exercise: what are the real dangers? Clin $\mathcal{F}$ Sports Med 1995:5:123-8.

8 Noakes TD. Fluid and electrolyte disturbances in heat illness. Int $\mathcal{f}$ Sports $8: 19 \cdot S 146-9$.

9 Holtzhausen L-M, Noakes TD. Collapsed ultraendurance athlete: proposed mechanisms and an approach to management. Clin 7 Sports Med 1997;7:292-301.

10 Noakes, TD. Hyperthermia, hypothermia and problems of hydration. In: Shephard RJ, ed. Endurance in sport, 2nd ed. London: Blackwell Publishers, 1999 (in press).

11 Herfel R, Stone CK, Koury SI, et al. Iatrogenic acute hyponatraemia in a college athlete. Br f Sports Med 1998:32:257-8.

12 Noakes TD. Fluid replacement during exercise. Exerc Sports Sci Rev 1993:21:297-330.

13 American College of Sports Medicine. Position stand on prevention of thermal injuries during distance running. Med Sci Sports Exerc 1987:19:529-33.

14 Irving RA, Noakes TD, Buck R, et al. Evaluation of renal function and fluid homeostasis during recovery from exercise induced hyponatremia. $7 \mathrm{Appl}$ Physiol 1991:70:342-8.

15 Holtzhausen L-M, Noakes TD, Kroning B, et al. Clinical and biochemical characteristics of collapsed ultramarathon runners. Med Sci Sports Exerc 1994:26:1095-101.

16 Nichol J, Schwellnus MP, Noakes TD. Serum electrolyte concentrations and hydration status in runners with exercise associated muscle cramping hydration status in runners with exercise associate
(EAMC). Med Sci Sports Exerc 1996:28(suppl 5):S59.

17 Schwellnus MP, Derman EW, Noakes TD. Aetiology of skeletal muscle "cramps" during exercise: a novel hypothesis. $\mathcal{\exists}$ Sports Sci 1997:15:277-85. 8 Bentley S. Exercise-induced muscle cramp. Proposed mechanisms and management. Sports Med 1996:21:409-20.

19 Nagra IS. Intravenous versus oral rehydration. Br 7 Sports Med 1998:32:265 20 Polak AA, van Linge B, Rutten FLPA, et al. Effect of intravenous fluid administration on recovery after running a marathon. Brf Sports Med 1993:27:205-8.

21 Noakes TD. J B Wolffe Lecture. Challenging beliefs: ex Africa semper aliquid novi. Med Sci Sports Exerc 1997:29:571-90.

22 Noakes TD. The hyponatremia of exercise. Int $\dot{\mathcal{F}}$ Sport Nutr 1992:2:205-28.

\section{You can run but you can't hide: the role of concussion severity scales in sport}

It should seem obvious to most clinicians that the management of concussion in sport requires a simple and reliable concussion severity scale. Such a scale may alert the clinician to the possibility of structural injury in the acute setting, determine return to sport strategies, predict length of disability, and provide the basis of management guidelines.

In severe traumatic brain injury, the widely used Glasgow coma scale provides the clinician with both a management strategy and the ability to reliably prognosticate about the ultimate outcome in each case. This scale is based on published validation studies. ${ }^{1}$ Unfortunately, when we consider concussive injuries, at last count there were at least 25 published scales of sports related concussive injury, none of which have been scientifically validated. $^{2}$ For the concussed athlete who wants to continue participation in sport, there is a very real risk that he or she may "shop around" for a scale that may not be in his best medical interests.

One of the most important conceptual points to appreciate when faced with an injury severity scale is the relation between concussion and mild brain injury. Concussion represents a subset of mild brain injury at the lowest end of the brain injury spectrum. When examined closely, many of the published schemes are actually surrogate measures of the whole spectrum of brain injury rather then being specific for the concussive injury. ${ }^{3-5}$

A further concern in concussive injury is that there is no single measure of injury severity that can be used in the same manner as conscious state within the Glasgow coma scale. For example, the common concussive symptoms of headache, amnesia, and loss of consciousness represent three domains that are physiologically and probably pathologically distinct. Yet the assumption of many of the various published scales is that they represent a linear continuum with headache being the most minor through to loss of consciousness representing the most "severe" symptom of concussive injury. ${ }^{5}$

We are also victims of our own clinical anecdotes. The "Colorado scale" originally proposed in 1991 was based on a single fatal case of head injury which occurred in American football. ${ }^{6}$ The authors then proposed an arbitrary concussion scale with the presence of loss of consciousness as 
the key symptom guiding management. No scientific evidence was presented for such an approach. This scale has subsequently been modified and has reappeared as the "American Academy of Neurology scale". ${ }^{7}$ The lack of scientific evidence for the validity of this scale is one factor that limits its usefulness. At least the American Academy of Neurology recognised this issue when they recommended this scale to be regarded at the level of a management "option" rather than a formal guideline.

There are also concussion scales that reflect traditional neurosurgical thinking. In these scales, the duration of loss of consciousness and post-traumatic amnesia become the prime determinants of injury severity. Although these may be outcome predictors for severe brain injury, their extrapolation to milder grades of brain injury remains speculative at best. ${ }^{689}$

One of the primary difficulties of virtually every grading scale is the problem of trying to be all-inclusive, whereas the practical needs in most concussive injury is for a scale biased toward distinguishing the trivial injury from the more severe injury. Many of the scales, however, are biased toward the higher severity injuries which in some cases include coma, persistent vegetative state, and death, far beyond the standard definition of concussion. ${ }^{3-5}$ Where other injury scales attempt to distinguish the trivial from more severe injuries, the evidence for their success is non-existent. ${ }^{10-14}$

\section{The ideal scale?}

As can be seen, a large number of concussion severity scaling systems exist, and not surprisingly clinicians and athletes are often confused by the conflicting advice that may be given by application of different scaling systems. In the era of medicolegal considerations in medicine, we need to consider the Clint Eastwood hypothesis - "you can run but you can't hide". The proponents of evidence based medicine will progressively marginalise enthusiastic clinicians that continue to promote their own severity scales in the absence of scientific validity.

The ideal concussion severity scale should be composed of the various domains of clinical and cognitive function but above all else must be prospectively validated in the sporting situation. Unlike the Glasgow coma scale, no single measure of brain function reflects different grades of concussion severity, thus either a spectrum of measures is required to encompass different aspects of brain function or possibly a time based separation of cognitive deficits.

PAUL R MCCRORY

Department of Medicine (Neurology), University of Melbourne, Austin and Repatriation Medical Centre, Heidelberg, Victoria, Australia 3084

Jennett B, Bond $\mathrm{M}$. Assessment of outcome after severe brain damage: a practical scale. Lancet $1975 ; 1: 480-4$

McCrory P. Were you knocked out? A team physician's approach to initial concussion management. Med Sci Sports Exerc 1997;29:S207-12.

3 Torg JF, ed. Athletic injuries to the head, neck and face, 2nd ed. St Louis: Mosby Year Book, 1991.

4 Gersoff W. Head and neck injuries. In: Reider B, ed. Sports medicine: the school age athlete. Philadelphia: WB Saunders, 1991.

5 Ommaya AK, Gennarelli TA. Cerebral concussion and traumatic unconsciousness: correlation of experimental and clinical observations on unconsciousness: correlation of experim

6 Kelly JP, Nichols JS, Filley CM, et al. Concussion in sports: guidelines for the prevention of catastrophic outcome. FAMA 1991;266:2867-9.

7 American Academy of Neurology. Practice parameter: the management of concussion in sports (summary statement). Neurology 1997;48:581-5.

8 Cantu RC. Guidelines for return to contact sports after cerebral concussion. Physician and Sportsmedicine 1986;14:75-83.

9 American Medical Society for Sports Medicine. Position statement on head injury, 1997.

10 Schneider RC. Head and neck injuries in football: mechanisms, treatment and prevention. Baltimore: Williams and Wilkins, 1973.

11 Kolb J. Cerebral concussion. Sports Training, Medicine and Rehabilitation 1989;1:165-71.

12 Kulund D. Athletic injuries to the head, neck and face. In: Kulund D, ed. The injured athlete. Philadelphia: JB Lippincott, 1982:225-57.

13 Nelson WE, Jane JA, Gieck JH. Minor head injury in sports: a new system of classification and management. Physician and Sportsmedicine 1984;12: 103-7.

14 Saal J. Common American football injuries. Sports Med 1991;12:132-47.

\section{Oxidative stress and exercise: need for antioxidant supplementation?}

Regular physical exercise is recognised to have many beneficial effects including reduction in the risk of both myocardial infarction and stroke, ${ }^{1}$ reduction in blood pressure, improved glucose tolerance, and decreased risk of osteoporosis. There may also be positive effects on the immune system. However, there has also been concern that these benefits may be outweighed by the production of free radicals and oxidative stress which is recognised to occur during physical exercise, ${ }^{2}$ particularly when the exercise is strenuous and erratic. Exercise increases oxygen utilisation and the flux of electrons through the mitochondrial electron transport chain with an associated increase in the production of free radicals. Ischaemia-reperfusion mechanisms and auto-oxidation of catecholamines may also contribute to the increased free radical production. There is reasonable evidence to suggest that the free radicals are intimately involved in exercise induced tissue and cell damage. Free radical production may overwhelm antioxidant defences (antioxidant enzymes, antioxidant vitamins, glutathione, and thiols) leading to oxidative stress and damage to lipids (lipid peroxidation), proteins, and DNA. The antioxidant defences are only likely to be overwhelmed when free radical production is excessive, such as during prolonged aerobic exercise, or when antioxidant defence is impaired.

Numerous studies in animals and humans have shown an increase in lipid peroxides following physical activity, ${ }^{3}$ although there are also studies showing no increases. ${ }^{4}$ There are also contradictory reports of damage to proteins and DNA. This may be explained by the different forms of exercise and animal species employed in the studies. There is debate as to whether the free radicals promote tissue injury or are products of such injury. Changes in antioxidant status also provide an indirect indicator of oxidative stress, pointing to a compromise of antioxidant defences induced by exercise. Reductions in the key aqueous phase antioxidant glutathione have been reported after a half marathon, ${ }^{5}$ and increases in the ratio of the oxidised form (GSSG) to the reduced form (GSH) have also been reported. ${ }^{6}$ Increased antioxidant enzyme activities (superoxide dismutase, catalase, and glutathione peroxidase) have been shown after exercise, ${ }^{7}$ and endurance training has been associated with lower tissue vitamin $\mathrm{E}$ concentrations. ${ }^{8}$ However, other studies suggest that most athletes have adequate antioxidant status as measured by vitamin A, C, and E. Indeed, highly trained athletes have been shown to have the highest levels of antioxidant 
protection in the form of vitamin $\mathrm{E}, \mathrm{GSH}$, and catalase activity $^{9}$; this may represent an adaptive response. There is therefore a lack of consistency in the results of investigations assessing endogenous antioxidant protection and exercise.

Because oxidative damage occurs with exercise, particularly in those who undertake irregular and strenuous activity, there has been much interest in the effects of antioxidant supplementation, both in terms of affecting performance and preventing tissue damage. Unfortunately, studies have provided equivocal results, although most would suggest that antioxidants may reduce exercise induced damage. Dillard et $a l^{10}$ showed that vitamin $\mathrm{E}$ could inhibit lipid peroxidation, as measured by expired breath pentane, induced by exercise. Other studies have further corroborated the benefits of vitamin $\mathrm{E}$ in attenuating exercise induced lipid peroxidation. ${ }^{11}$ However, there appears to be no effect of vitamin $\mathrm{E}$ in reducing exercise induced muscle injury, as measured by creatinine kinase and lactate dehydrogenase in the blood after strenuous exercise. $N$-Acetylcysteine given to human volunteers has been noted to have a beneficial effect on fatigue development. ${ }^{12}$ Vitamin C (ascorbate) can act not only as an antioxidant but also as a pro-oxidant, by reducing ferric ions to ferrous ions, which can then catalyse the Fenton reaction with the production of the hydroxyl radical. Antioxidant mixtures have also been used and have mostly been associated with reduced markers of lipid peroxidation after exercise. ${ }^{13}$ Other studies have assessed the effects of muscle soreness as a feature of exercise induced muscle damage. Again equivocal results have been found, although one study using vitamin $\mathrm{C}$ supplementation reduced muscle soreness after exercise. With regard to the issue of vitamin supplementation and exercise performance, most studies have shown little benefit, ${ }^{14}$ although others have found positive effects. ${ }^{15}$ There is no doubt that, in the world of highly competitive sport, even the smallest benefit could mean the difference between winning and losing.

What then can we conclude about the antioxidant status of those who indulge in physical exercise? There is little doubt that oxidative damage occurs with exercise and that antioxidant supplementation may reduce that damage. However, it is still uncertain as to which antioxidant(s) is (are) the most beneficial and the amounts required. No studies have shown any long term health benefits of antioxidant supplementation in athletes. There is also concern that some antioxidants may act paradoxically as prooxidants under certain situations, particularly when used in large doses - for example, vitamin C. The paucity of data on the long term effects of megadoses of antioxidants suggests that caution is required at present. Indeed, there is little evidence that athletes are deficient in antioxidants, and therefore many would argue that adequate amounts of antioxidants can be obtained from the diet or simple multivitamin/mineral supplementation to no more than the recommended daily allowance. This policy will certainly maximise the benefits of exercise and reduce its potential deleterious effects. It would also appear that those who exercise regularly are less prone to oxidative damage than the irregular erratic participant in sporting activities, and this may be the subgroup who specifically require antioxidant supplementation. At present, there is little evidence of any beneficial effect of antioxidant supplementation on physical performance.

PETER SHARPE

Department of Clinical Biochemistry,

Craigavon Area Hospital,

Portadown,

Craigavon BT63 5QQ,

$N$ Ireland

1 Salonen JT, Pusha P, Tuomilento J. Physical activity and risk of myocardial infarction, cerebral stroke and death. Am f Epidemiol 1982;115:526-37.

2 Davies KJA, Quintanilha AT, Brooks GA, et al. Free radicals and tissue damage produced by exercise. Biochem Biophys Res Commun 1982;107: $1178-205$.

3 Kanter MM, Lesmes GR, Kaminsky LA, et al. Serum creatine kinase and lactate dehydrogenase changes following an eighty kilometer race. Eur $\mathcal{f}$ Appl Physiol 1988;57:60-3.

4 Dernbach AR, Sherman WM, Simonsen JC, et al. No evidence of oxidant stress during high intensity rowing training. $\mathcal{F}$ Appl Physiol 1993;74:2140-5. 5 Duthrie GG, Robertson JD, Maughan RJ, et al. Blood antioxidant status and erythrocyte lipid peroxidation following distance running. Arch Biochem Biophys 1990;282:78-83.

6 Gohil K, Viguie C, Stanley WC, et al. Blood glutathione oxidation during human exercise. F Appl Physiol 1988;69:115-19.

7 Ji LL. Antioxidant enzyme response to exercise and aging. Med Sci Sports Exerc 1993;25:225-31

8 Aikawa KM, Quintanilha AT, de Lumen BO, et al. Exercise endurance training alters vitamin $\mathrm{E}$ tissue level and red blood cell haemolysis in rodents. Biosci Rep 1984;4:253-7.

9 Robertson JD, Maughan RJ, Duthie GG, et al. Increased blood antioxidant systems of runners in response to training load. Clin Sci 1991;80:611-18.

10 Dillard CJ, Litov RE, Savin WM, et al. Effects of exercise, vitamin E and ozone on pulmonary function and lipid peroxidation. $\mathcal{F}$ Appl Physiol 1978; 45:927-32.

11 Sumida S, Tanaka K, Kitao H, et al. Exercise-induced lipid peroxidation and leakage of enzymes before and after vitamin $\mathrm{E}$ supplementation. Int $\mathcal{F}$ Biochem 1989;21:835-8

12 Reid MB, Stokic DS, Koch SM, et al. N-acetylcysteine inhibits muscle fatigue in humans. $\mathcal{F}$ Clin Invest 1994;94:2468-74.

13 Kanter MM, Nolte LA, Holloszy JO. Effects of an antioxidant vitamin mixture on lipid peroxidation at rest and post-exercise. F Appl Physiol 1993;74: 965-9.

14 Rokitzki L, Logemann E, Huber G, et al. $\alpha$ Tocopherol supplementation in racing cyclists during extreme endurance training. Int f Sport Nutr 1994;4: 253-64.

15 Simon-Schnass I, Pabst H. Influence of vitamin E on physical performance. Int 7 Vitam Nutr Res 1988;58:49-54.
In 1965 the UK government banned television advertisements for cigarettes. This was the first response to the seminal report of the 1962 Royal College of Physicians report on tobacco and health. We now know that about 120000 people die prematurely each year as a result of smoking, and millions are addicted to nicotine or harmed in other ways. ${ }^{1}$

Over 20 years after the TV advertising ban, surveys showed that almost two thirds of schoolchildren still thought cigarettes were often or sometimes advertised on television. ${ }^{2}$ What had happened? The tobacco industry's marketing budgets, like big balloons full of money, had been squeezed out of TV advertising but had bulged into sponsorship of sport-especially televised sport. Sponsorship is the continuation of tobacco advertising by other means-including through the previously inaccessible BBC. Embassy snooker achieved 376 hours of TV coverage and cumulative viewers of 385 million in the 1996-97 season. ${ }^{3}$ Some sports have admirably resisted the tainted tobacco dollar-notably, association football and the Olympics - but many others, such as cricket, rugby and snooker, have offered a willing vehicle for promoting tobacco. Sport, with its associations with action and youth, offers excellent images and role models to the tobacco industry. This is especially important in recruiting young smokers-a process of exciting experimentation eventually 
consolidated by addiction. The approach is described in a tobacco industry internal document (Morris P. Why one smokes. 1969) as follows:

"A cigarette for the beginner is a symbolic act. I am no longer my mother's child, I'm tough, I am an adventurer, I'm not square ... As the force from the psychological symbolism subsides, the pharmacological effect takes over to sustain the habit."

When the Indian associate of the British American Tobacco group sponsored the Indian World Cup Cricket team in 1996 with its Wills brand, a survey showed that smoking among Indian teenagers increased fivefold. There was also a marked increase in false perceptions such as, "You become a better cricketer if you smoke Wills" and "teams with more Wills smokers will fare better". ${ }^{4}$ Contrary to the widely held perception among school children, the Indian cricket team had no smokers at all. Sport sponsorship also helps to "normalise" tobacco use and provide a rationalisation for continued use. For example one UK survey ${ }^{5}$ put the statement: "smoking can't be all that dangerous, or the government would ban sports sponsorship by tobacco companies" to over 4000 11-16 year olds. Substantially more smokers agreed with this statement and only one in four $(26 \%)$ disagreed, which suggests these young smokers were drawing reassurance from the association between sport and tobacco.

The major counter argument advanced by the tobacco companies and their fellow travellers in sponsored sports is that promotional activities merely influence the choice of brand. This means, they claim, that the total amount of tobacco smoked, and therefore the harm caused, is not influenced by advertising campaigns. The influence of any advertising is hard to measure, but econometric studies do successfully correlate advertising expenditure and tobacco consumption. ${ }^{6}$ Under the Conservatives, who had no wish to ban tobacco advertising, government economists found that "The balance of evidence thus supports the conclusion that advertising does have a positive effect on consumption." And where smoking had been banned: "In each case the banning of advertising was followed by a fall in smoking on a scale which cannot be reasonably attributed to other factors." " Studies by the World Bank ${ }^{8}$ and US surgeon general $^{9}$ reached similar conclusions. Honest advertising professionals are not surprised by the link between advertising and increased smoking - if an advertisement can persuade a consumer to switch tobacco brands, why shouldn't it switch expenditure from nontobacco products, such as football tickets, beer, or kebabs, to cigarettes? The World Bank's background paper on tobacco advertising ${ }^{8}$ suggests that the "European Union's ban could reduce cigarette consumption by nearly $7 \%$." Even this relatively small reduction would translate to tens of thousands of avoided premature deaths in the European Union each year.

The government and EU have acted to eliminate tobacco sponsorship by 2003, with an extension until 2006 for World events. ${ }^{10}$ This is both too slow and unnecessary, and the inescapable consequence will be more entirely avoidable death and illness - something that should weigh heavily in assessment of the risks to tobacco sponsored sports. Despite dire warnings and much anguish among tobacco sponsored sports, tobacco sponsorship in Australia was phased out quickly and without casualties. We already see great progress in the biggest tobacco sponsored sport, Formula One. In July the Williams team announced it would replace Rothmans with BMW as its prime sponsor. Other automotive and electronics companies are assessing their opportunities. Few will be prepared to be as generous as tobacco and some modest downsizing may be needed, but in Formula One the tobacco money simply fuels the grossly inflated salaries of drivers and a technology "arms race" that has deprived the sport of some of its excitement. The delay to 2003 or 2006 in phasing out tobacco sponsorship is a mistake. New sponsors will be reluctant to start negotiations in competition with the tobacco companies until there are events available to sponsor. We suspect that nothing much will happen until 2002, then there will be a flurry of intense activity. Suppose the government had announced that Embassy World Cup Snooker would need a new sponsor in 2000. Does anybody seriously believe that a new sponsor, interested in hundreds of hours of TV coverage, would not be found? Under current proposals snooker will have to wait until 2006 to find new sponsors.

It is important to recognise the consequences of tobacco promotion through sports sponsorship. Through a chain of cause and effect, tobacco sponsorship helps to nurture smoking in children and adults, which ultimately leads to illness and untimely death. Delaying until 2003 or 2006 just prolongs the agony.

CLIVE BATES

Director, Action on Smoking and Health

102 Clifton Street

London EC2A $4 H W$

Email:clive.bates@dial.pipex.com

1 Callum C. The UK smoking epidemic: deaths in 1995. London: Health Education Authority, 1998.

Carrick James market research, quota sample of 5-16 year olds, 1989. Beating the ban. London: Health Education Authority, 1990.

3 World Professional Billiards and Snooker Association. A sport made for television. Embassy World Snooker web site: http://

4 Vaidya SG, Naik UD, Vaidya IS. Effects of sports sponsorship by tobacco companies on children's experimentation with tobacco. BMF 1996;313: 400 .

5 Mori Research Ltd. Schools omnibus survey. London: Mori, 1996.

6 Andrews RL, Franke GR. The determinants of cigarette consumption: a meta-analysis. Fournal of Public Policy and Marketing 1991;10:81-100.

7 Smee C. Effect of tobacco advertising on tobacco consumption: a discussion document reviewing the evidence. London: Economic and Operational Research Division, Department of Health, 1992

8 Jha P, Chaloupka F, eds. Curbing the epidemic: governments and the economics of tobacco control. Washington: World Bank, 1999.

9 US surgeon general. Reducing the health consequences of smoking-25 years of progress. Rockville, Maryland: US Department for Health and Human progress. Rockices, 1989.

10 European Union directive 98/43/EC 